\title{
MEMAHAMI KOMUNIKASI BEDA BUDAYA ANTARA SUKU BATAK TOBA DENGAN SUKU JAWA DI KOTA SEMARANG (STUDI PADA MAHASISWA SUKU BATAK TOBA DENGAN SUKU JAWA DI UNIVERSITAS SEMARANG)
}

\author{
Debora Simbolon \\ (gloria_sanadi@gmail.com)
}

(Mahasiswa S1 Program Studi Ilmu Komunikasi Universitas Semarang)

\begin{abstract}
The development of increasing open world on various aspects of human life which is supported by the mobility and movement and exchange of information quickly. The information of exchage is quickly explain the fact that all human beings can not circumvent intercultural communication.

The results of this study explains the theory and science of communication theory explain Phenomenology by Maurice Marleu-Ponty (Littlejohn 1999) is the assumption informants from the experiences and try to understand every event in their environment with personal experiences.

The research method used is descriptive qualitative analysis, it is a process of focusing attention on the simplification and transformation of the raw data that comes from the written notes in the field, the presentation of the data is done by using a form of narrative text, drawing conclusions and verification.

Different cultural communication barriers conflict for communicators. Language and ethnosentrism be one of the triggers of conflict, such as Batak's language that is considered rude to make Javanise misunderstand the message. Solutions to communication barriers that are of mutual respect and learn from each other, for example Javanise learning Batak's langguage and Bataknese learning Javanese's langguage.
\end{abstract}

Keywords : Komunikasi Interkultural, Resistensi, Solusi.

\section{Pendahuluan}

Perkembangan dunia semakin terbuka pada berbagai aspek kehidupan manusia. Perpindahan dan pertukaran informasi secara cepat menjelaskan tentang kenyataan bahwa semua manusia tidak bisa mengelak dari komunikasi antar budaya. Proses komunikasi sangat vital dan mendasar bagi komunikasi sosial, dikatakan vital karena setiap individu memiliki kemampuan untuk berkomunikasi dengan individu yang lainnya, dengan begitu menetapkan kredibilitasnya sebagai seorang anggota masyarakat dan dikatakan mendasar karena manusia baik yang primitif maupun yang modern berkeinginan mempertahankan suatu persetujuan mengenai berbagai hal aturan sosial komunikasi. Oleh karena itu yang harus ditekankan adalah bagaimana komunikasi bisa berjalan efektif dan efisien sehingga pesan yang diterima, ditafsirkan sama antara komunikator dan komunikan. Artinya komunikasi yang efektif, terjadi tidak hanya sekedar saat seseorang telah melekatkan arti tertentu terhadap perilaku orang lain tetapi juga pada persepsinya yang sesuai dengan pemberi pesan atau informasi. 
Berdasarkan pengalaman peneliti budaya Batak Toba adalah salah satu jenis suku Batak yang mendominasi diantara suku Batak lainnya khususnya di kota Semarang. Hal ini dikarenakan suku Batak Toba memiliki jumlah yang relatif banyak jika dibandingkan dengan suku Batak lainnya. Suku Batak Toba juga memiliki sifat yang sangat menonjol dibandingkan dengan suku batak lainnya yaitu suku Batak Toba selalu membawa kebiasaannya dalam berkomunikasi kemana pun mereka berada. Mereka selalu mempertahankan cara berkomunikasi mereka yang keras dengan logat Batak Toba yang sangat menonjol. Hal ini membuat suku Batak Toba mudah dikenali dan terlihat lebih menonjol dalam suatu komunitasnya.

Hal inilah yang memotivasi peneliti untuk mengkaji bagaimana cara atau praktek komunikasi beda budaya dalam kampus Universitas Semarang, khususnya suku Batak Toba dan Jawa. Pola interaksi komunikasi beda budaya antara suku Batak Toba dengan suku Jawa yang ada pada komunitas Universitas Semarang. Semula seorang pria bersuku Jawa mengeluh ketika berkenalan dengan seorang pria suku Batak Toba. Pada saat berkenalan dengan suara keras dan lantang orang Batak Toba memperkenalkan dirinya kepada orang Jawa yang bernada lembut dan pelan. Karena kaget mendengar suara orang Batak Toba yang keras tersebut, orang Jawa bergumun dalam hati orang batak keras sekali dan menyebabkan adanya jarak diantara mereka. Pola kumunikasi yang biasa dilakukan orang batak Toba yang dianggap keras, kasar, dan ceplas-ceplos berbeda dengan pola komunikasi orang Jawa yang terkesan sopan, lemah lembut, halus, ramah mendorong peneliti mengkaji hal ini. Peneliti ingin memaparkan bagaimana hambatan komunikasi beda budaya yang dilakukan oleh suku Batak Toba dengan suku Jawa serta solusi yang mereka lakukan dalam menangani hambatan komunikasi beda budaya tersebut.

\section{Tinjauan Pustaka \\ Fenomenologi}

Bogan dan Tailor dalam (Gunawan Witjaksana, 2005) bahwa fenomenologi memandang perilaku manusia, apa yang mereka katakan, apa yang mereka lakukan sebagai suatu produk dari bagaimana orang melakukan tafsir terhadap dunia mereka sendiri. Dengan kata lain untuk menangkap makna perilaku seseorang, peneliti harus bisa melihat makna segalanya dari pandangan orang yang terlibat dalam situasi yang terkait dengan penelitiannya tersebut (participant's point view).

Perlu dipahami bahwa makna ekspresi manusia selalu terkait dan tidak mungkin dipisahkan dari konteksnya. Dengan demikian untuk bisa memahami ekspresi orang harus bisa memahami konteksnya serta ekspresi dari masingmasing individu. Hermeneutika mempersyaratkan suatu aktifitas konstan dari interpretasi antar bagian dengan keseluruhannya yang merupakan proses tanpa awl dan tanpa akhir (Smith dan Heshusius, dalam Gunawan Wijaksana, 2005). Pendekatan ini berusaha memahami makna dari berbagai peristiwa dan interaksi manusia dalam situasi yang khusus. Dalam penelitian ini, peneliti mencoba mengkaji fenomena yang terjadi dari komunikasi beda budaya yang dilakukan suku Jawa dan suku Batak Toba. Pada penelitian ini peneliti akan diam dan menganggap dirinya tidak mengetahui segala sesuatu yang terjadi serta sedang mempelajari interpretasi yang muncul.. 


\section{Teori Interaksionisme Simbolik}

Teori interaksi simbolik melihat individu sebagai pelaku aktif, reflektif dan kreatif, menafsirkan, menampilkan perilaku yang rumit dan sulit diramalkan. Teori interaksi simbolik fokus pada soal diri sendiri dengan segala atribut luarnya. Deddy Mulyana mengutip istilah yang digunakan Cooley yaitu looking glass self (Mulyana, 2001: 50). Gagasan diri ala Cooley ini terdiri dari tiga komponen.

\section{Individu}

mengembangkan bagaimana dia tampil bagi orang lain;

2. Individu membayangkan bagaimana penilaian mereka atas penampilan individu tersebut;

\section{Individu}

mengembangkan sejenis perasaan-diri, seperti kebanggaan atau malu, sebagai akibat membayangkan penilaian orang lain tersebut.

Pada penelitian ini penulis akan melihat bagaimana interaksi baik secara verbal maupun non verbal yang dilakukan oleh beda suku yaitu suku Jawa dan suku Batak Toba. Penulis akan memafarkan secara jelas bentukbentuk interaksi dari masing-masing budaya yaitu interaksi yang ada didalam suku Jawa maupun suku Batak Toba. Selain itu penulis juga akan mengkaji bagaimana penyatuan dua suku yang berbeda lewat interkasi simbolik yang dilakukan dari komunikasi beda budaya yaitu budaya Jawa maupun budaya Batak Toba.

\section{Hambatan Komunikasi Budaya}

Hambatan komunikasi atau yang juga dikenal sebagai communication barrier adalah segala sesuatu yang menjadi penghalang untuk terjadinya komunikasi yang efektif (Chaney dan Martin, 2004: 11). Menurut Chaney dan Martin hambatan dalam komunikasi antar budaya dibedakan menjadi dua jenis besar yaitu hambatan diatas air (above waterline) dan bawah air (below waterline). Faktor-faktor hambatan komunikasi antar budaya yang berada dibawah air (below waterline) adalah faktor-faktor yang membentuk perilaku atau sikap seseorang, hambatan jenis ini cukup sulit untuk dilihat atau diperhatikan. Jenis-jenis hambatan yang termasuk dalam below waterline adalah persepsi (perceptions), norma (norms), stereotip (stereotypes), filosofi bisnis (business philosophy), aturan (rules), jaringan (networks), nilai (values), dan grup cabang (subcultures group).

Salah satu cara untuk menentukan dan membedakan konteks, dapat diidentifikasikan melalui pengaruh karakteristik komunikasi terhadap komunikasi. Beberapa pengarang telah menyusun karakteristik komunikasi berdasarkan: jumlah komunikator, derajat proksimitis fisik, jumlah saluran sensoris yang mungkin dapat digunakan komunikator dan kecepatan reaksi umpan balik (Miller dan Sarah Trenholm, 1995: 20). Bahasa juga merupakan kunci sukses suatu proses komunikasi. Dengan bahasa perbedaan dalam berkomunikasi dapat diminimalisir. Ada dua definisi bahasa. Definisi yang pertama bahasa berasal dari pandangan tentang kesadaran yang luar biasa tentang Social Self. Definisi yang kedua merupakan pandangan dari sebuah hipotesis kemahatahuan para pengamat tentang seluruh sistem mind manusia. Dua definisi itu sangat berbeda satu sama lain, dan gagal membuat satu keputusan yang tepat tentang bahasa. Bahasa menurut Social Self Definition adalah sistem komunikasi manusia dengan menggunakan bahasa; dan menurut Whole System Definition bahasa adalah sebuah sistem pengembangan psikologi individu dalam sebuah konteks intersubjektif (Alo Liliweri, 2010: 63). 


\section{Metodologi Penelitian}

Penelitian ini, menggunakan pendekatan model analisis deskriptif kualitatif. Metode analisis deskriptif kualitatif yang dilakukan pada penelitian ini dimaksud untuk memungkinkan sesorang membuat pengertian tentang berbagai hal yang dialaminya. Seperti yang dinyatakan Spilgelberg (dalam Gunawan Witjakana, 2005) deskripsi kualitatif mempersyaratkan suatu usaha dengan keterbukaan piker untuk merumuskan subjek yang sedang diteliti.

Metode deskriptif pada hakekatnya adalah mencari teori, bukan menguji teori. Metode ini menitikberatkan pada observasi dan suasana alamiah. Peneliti bertindak sebagai pengamat. Ia hanya membuat kategori pelaku, mengamati gejala dan mencatatnya dalam buku observasi. Dengan suasana alamiah berarti peneliti terjun ke lapangan. Ia tidak berusaha memanipulasi variabel karena kehadirannya mungkin mempengaruhi gejala, peneliti harus berusaha memperkecil pengaruh tersebut (Lexy. J. Moleong, 2002: 34).

Jenis data dalam penelitian ini dibagi dalam bentuk data primer dan data sekunder. Data Primer adalah data yang diperoleh secara kasat mata dari narasumber melalui wawancara langsung. Data primer yang diperoleh dalam penelitian ini adalah hasil pengamatan secara langsung dengan informan berupa hasil wawancara. Sumber data dalam penelitian ini adalah informan atau narasumber yang terdiri suku Batak Toba yang lahir dan besar didaerah asal serta suku Jawa yang lahir dan besar di kota Semarang khususnya yang kuliah di Universistas Semarang. Sedangkan data sekunder adalah data tertulis yang diperoleh dalam bentuk jadi, dikumpulkan dan diolah. Sumber data sekunder yang digunakan penulis adalah arsip dan dokumentasi mengenai peradaban suku Batak Toba dengan suku Jawa (Santoso, 2004: 22).

Menurut Patton (dalam Gunawan Witjaksana, 2005), purposive sumpling adalah peneliti mendasarkan pada landasan teori yang digunakannya, keinginan pribadi, karakteristik empiris yang dihadapi karena itu pemilihan sampling lebih cenderung didasarkan pada penguasaan/pemilikan informasi terkait dengan penelitian yang sedang peneliti lakukan bahkan dalam pelaksanaan dan pengumpulan informan dapat berkembang sesuai dengan kebutuhan dan kemantapan peneliti dalam memperoleh data. Dalam penelitian ini, peneliti membatasi informan yang akan digali informasinya. Karakter informan yang dijadikan sampel dalam penelitian ini adalah:

- Mahasiswa Universitas Semarang

- Mahasiswa Universitas Semarang yang berasal dari suku Batak Toba

- Mahasiswa Universitas Semarang yang berasal dari suku Jawa

- Mahasiswa Universitas Semarang yang berasal dari suku Batak Toba dan suku Jawa yang saling berinteraksi setiap hari.

Pengumpulan data adalah suatu proses pengadaan data primer untuk keperluan penelitian. Dalam penelitian ini, pengumpulan data akan dilakukan langsung oleh peneliti dalam situasi yang sesungguhnya. Teknik pengumpulan data dalam penelitian ini yang digunakan adalah data dokumentasi, wawancara mendalam yang berhubungan dengan data yang diperlukan dan observasi.

Penelitian menggunakan teknik trianggulasi data untuk menentukan meningkatkan validitas data yang diperoleh. Menurut Patton (dalam 
Gunawan Wijaksana, 2005) trianggulasi data disebut juga dengan trianggulasi sumber artinya peneliti diarahkan untuk mengumpulkan data dan peneliti wajib mengumpulkan data dari berbagai narasumber yang terkait dengan penelitian. Dengan demikian, apa yang ditulis dari sumber satu dengan yang lain bisa diuji kebenarannya baik kelompok sumber sejenis maupun sumber-sember yang berbeda jenisnya.

Tahap analisis data dalam penelitian kualitatif secara umum dimulai sejak pengumpulan data, yang terdiri dari:

1) reduksi data, yang diartikan sebagai proses pemilihan, pemusatan perhatian pada penyederhanaan, pengabstrakan dan transformasi data kasar yang muncul dari catatancatatan tertulis di lapangan

2) penyajian data (display data) dilakukan dengan menggunakan bentuk teks naratif

3) penarikan kesimpulan serta verifikasi.

\section{Hasil dan Pembahasan}

Budaya Batak Toba sarat dengan "MARGA" dimana lewat marga orang Batak Toba mampu memahami hubungan dan adat istiadat mereka sendiri. Marga dalam suku Batak Toba disebut juga kelompok genelogis, persekutuan dari orang-orang bersaudara, se-darah, yang mempunyai nama tersendiri, se-keturunan menurut garis satu bapak leluhur. Menurut hukum adat marga itu merupakan suatu kesatuan karena: kekerabatan darah sebagai 'dongan sabutuha' (yang berasal dari rahim yang sama), larangan endogami, solidaritas satu sama lain, satu komunitas kurban, mempunyai tanah sendiri (golat) dan hubungan perkawinan, (Promes, 1996: 18).

Sifat dan tingkah laku orang Batak Toba, sangat dipengaruhi atau dapat dikatakan dibentuk oleh kondisi geografis, lingkungan (environment), dan iklim di tanah Batak Toba (katakanlah determinasi lingkungan). Pada awalnya, yang disebut sebagai tanah Batak Toba adalah daerah di sekitar Danau Toba namun seiring jalannya waktu orang-orang Batak Toba kemudian menyebar ke seluruh daerah provinsi Sumatera Utara dan wilayah lain diseluruh Indonesia dan membentuk wilayah masing-masing dan membawa serta adat batak kedalam wilayah yang baru mereka temui.

Sementara itu pada percakapan sehari-hari suku Jawa sangat memperhatikan kaidah bahasa. Menurut falsafah suku Jawa yang paling tahu baik buruknya dan tepat kelirunya kaidah bahasa yang digunakan seseorang penutur tentu saja penuturpenutur bahasa yang bersangkutan, karena merekalah yang menguasai dengan sepenuh penghayatan bahasa yang berlaku dalam kehidupan bermasyarakat. Pengetahuan dan kemampuan mengetahui itu telah menjadi sebagian dari dirinya dan ada sebagai intuisi kebahasaan. Hal ini lah yang melandasi mengapa dalam kehidupan sehari-hari bahasa suku Jawa selalu lebih halus dan memperhatikan kaidah-kaidah yang berlaku sesuai adat suku Jawa.

Dari segi bahasa sebenarnya suku Jawa juga memiliki empat tingkatan kasar lembutnya yaitu yang pertama Ngoko adalah bahasa yang digunakan dalam kehidupan sehari-hari, yang kedua Ngoko alus adalah gabungan dari bahasa ngoko dan kromo inggil dimana bahasa ini digunakan untuk orang yang dianggap lebih tinggi derajatnya baik dari segi jabatan, ilmu pengetahuan, umur dan status sosialnya, yang ketiga Kromo adalah bahasa yang menggunakan bahasa kromo inggil biasanya digunakan untuk berbicara 
dengan orang lain dimana kata awal dan akhirnya tidak perlu dikrama inggilkan, yang empat Kromo Alus adalah bahasa yang menggunakan gabungan dari krama dan krama inggil dan katakatanya jauh lebih halus dan sopan serta awal dan akhir kalimat sudah ikut dikramakan, (Sudaryanto, 1992: 5).

Beda budaya beda kebiasaan, beda kebiasaan beda persepsi. Perbedaan persepsi antar budaya akan menemukan kesalah-pahaman dalam berkomunikasi apabila kita tidak menyadari berbagai hambatan komunikasi yang muncul. Satu pemahaman yang harus kita tanamkan saat berkomunikasi dengan orang lain adalah bahwa beda budaya beda cara berkomunikasi. Hal ini ditemukan dalam komunikasi beda budaya yang dilakukan oleh suku Jawa dan Batak Toba yang tinggal dalam satu tempat tinggal kost. Tidak jarang dari mereka menemukan pertengkaran kecil akibat terjadinya kesalah-pahaman diantara mereka. Berikut beberapa hambatan yang terjadi dalam komunikasi beda budaya yang dilakukan oleh masingmasing informan:

1. Bahasa. Beda budaya beda pula bahasa. Perbedaan bahasa antara bahasa Jawa dengan bahasa Batak Toba yang cukup mencolok memberikan kesulitan berkomunikasi anatara suku Jawa dengan suku Batak Toba.

2. Fisik. Secara fisik suku Jawa lebih menarik dan lembut jika dibandingkan dengan suku Batak Toba.

3. Budaya. Budaya suku Jawa dan suku Batak Toba sangat berbeda jauh. Hal ini disebabkan situasi sosio-kultural dan agama yang dianut juga berbeda.

4. Persepsi. Persepsi akan suku Batak Toba yang keras dan kasar dan suku Jawa yang lembut dan halus sudah buka rahasia umum lagi.
5. Emosi. Suku Jawa sangat sulit menunjukan sikap emosionalnya

Pada penelitian ini, peneliti merangkum berbagai cara yang dapat dilakukan oleh masing-masing informan untuk mengurangi hambatan komunikasi yang terjadi dalam kehidupan sehari-hari di tempat tinggal kost. Ada beberapa cara berkomunikasi yang dilakukan oleh masing-masing informan dalam berinteraksi dalam kehidupan sehari-hari diantaranya:

1. Suku Batak Toba yang merupakan suku pendatang di kota Semarang harus bisa beradaptasi dengan lingkungan yang ia temui.

2. Menghormati nilai budaya daerah yang masih dipegang teguh

3. Tidak terkesan seperti orang paling pintar dan mau menguasai dalam lingkungan.

Dengan adaptasi dan cara komunikasi yang dilakukan diatas, peneliti menemukan suatu kerukunan yang baik dalam lingkungan tempat tinggal kost dimana antara suku Batak Toba yang semula dikenal keras bisa melebur dengan suku Jawa yang dikenal dengan lembut. Hal ini dikarenakan dua faktor yaitu diantaranya:

1. Sikap saling terbuka menerima unpan balik (feed Back) antara suku Jawa dengan suku Batak Toba.

2. Baik suku Jawa maupun suku Batak Toba menyusun secara terperinci apa, dan kapan informasi tersebut harus disampaikan dan kepada siapa informasi tersebut akan disampaikan.

\section{Kesimpulan}

Kesimpulan yang dilakukan peneliti mengenai komunikasi beda budaya yang dilakukan suku Batak Toba dengan suku Jawa dalam lingkungan tempat tinggal kost ada 2 yaitu:

1. Hambatan komunikasi yang dialami masing-masing informan adalah 
perbedaan bahasa serta sifat etnosentrisme

2. Cara berkomunikasi yang dilakukan suku Batak Toba untuk mengurangi hambatan komunikasi yang terjadi adalah dengan memahami dan saling menghargai perbedaan masingmasing suku.

\section{Daftar Pustaka}

Alo Liliweri, 2007. Dasar-dasar Komunikasi Antar Budaya. Yogyakarta. Pustaka Pelajar

Berger and Arthur Asa. 2000. Tandatanda dalam kebudayaan kontemporer. (edisi terjemahan oleh M.Dwi Mariyanto \& Sunarto). Jogyakarta. Tiara wacana Yogya

Deddy Mulyana. 2001. Metodologi Penelitian Kualitatif; Paradigma Baru Ilmu Komunikasi dan Ilmu Sosial Lainnya. Bandung: Remaja Rosdakarya 2005, Ilmu Komunikasi: Suatu Pengantar. Bandung: Remaja Rosdakarya.

Gunawan Witjaksana. 2005, PokokPokok Pikiran dalam Metodologi Penelitian Komunikasi Kualitatif. Buku ajar Ilmu Komunikasi. USM

Heimstra. N.W and Mc. Farling, LH. 1982. Environmental Psychology. California: brooks Cole Publishing Company.

Humala Simanjuntak. 2005. Dalihan Na - Cet.1 Jakarta: Perpustakaan Nasional Indonesia

Jalaludin Rakhmat. 1994. Psikologi Komunikasi. Bandung: Remaja Rosdakarya.

Koencoroningrat. 1981. Metode-Metode Penelitian Masyarakat. Jakarta: gramedia Pustaka utama. 1981
Lexy. J. Moleong.2002. Metodologi Penelitian Kualitatif. Cet. 13 Bandung: Remaja Rosdakarya

Littlejohn. 1999. Theories of Human Communication. Belmont, California: Wadsworth Publishing Company

M. Iqbal Hasan. 2002. Pokok-pokok Materi Metodologi Penelitian dan Aplikasinya. Cet. 1. Jakarta: Ghalia Indonesia

Promes OFM.CAP. 1996. Silsilah Batak. Pematang Siantar. Bina Media

Samovar. Larry A, Porter. Richard E, McDaniel. Edwin R2010. Komunikasi Lintas Budaya. (edisi terjemahan oleh Indri Margaretha Sidabalok). Jakarta. Salemba Humanika

Sudaryanto. 1991. Tata Bahasa Baku Bahasa Jawa. Cet.1: Yogyakarta. Duta Wacana University Press. 